\title{
Nicotine Activating a4 $\beta 2$ Nicotinic Acetylcholine Receptors to Suppress Neuroinflammation via JAK2-STAT3 Signaling Pathway in Ischemic Rats and Inflammatory Cells
}

\section{Qi Wang}

The First Hospital of China Medical University: The First Affiliated Hospital of China Medical University

Jinyu Gou

Shanghai Jiaotong University School of Medicine Xinhua Hospital

\section{Shenrui Guo}

Shanghai Jiaotong University School of Medicine Xinhua Hospital

\section{Feng Wei}

Shanghai Jiaotong University School of Medicine Xinhua Hospital

\section{Tingting Han}

Chifeng Clinical Medical School of Inner Mongolia Medical University: Chifeng Municipal Hospital

\section{Ruihe Lai}

Nanjing Drum Tower Hospital: Nanjing University Medical School Affiliated Nanjing Drum Tower Hospital

\section{Dalong Zhang}

The First Hospital of China Medical University: The First Affiliated Hospital of China Medical University

\section{Yao Diao}

The First Hospital of China Medical University: The First Affiliated Hospital of China Medical University

Yafu Yin ( $\nabla$ yinyf-2001@163.com )

Shanghai Jiaotong University School of Medicine Xinhua Hospital https://orcid.org/0000-0002-4818-6655

\section{Research Article}

Keywords: cognitive impairment, a4ß2 nicotine acetylcholine receptor, nicotine, JAK2-STAT3, neuroinflammation

Posted Date: December 14th, 2021

DOI: https://doi.org/10.21203/rs.3.rs-1150604/v1

License: (a) (i) This work is licensed under a Creative Commons Attribution 4.0 International License. Read Full License

Version of Record: A version of this preprint was published at Molecular Neurobiology on March 17th, 2022. See the published version at https://doi.org/10.1007/s12035-022-02797-4. 


\section{Abstract}

Nicotine plays a role in inhibiting the inflammatory factors, which contributes to improving cognitive impairment by activating $a_{4} \beta_{2} n A C h R s$ in ischemic rats, but the underling mechanism has not been fully elucidated. Janus tyrosine kinase 2-signal transducer and activator of transcription 3 (JAK2-STAT3) signaling pathway is involved in cognitive improvement, and there seems a relationship between nAChRs and JAK2-STAT3 as well. This study was designed to investigate the role of JAK2STAT3 signaling pathway in nicotine-mediated anti-inflammation effect. Nicotine, DH $\beta E$ (the most potent competitive antagonist of $a_{4} \beta_{2} n A C h R s$ ) and AG490 (a specific JAK2-STAT3 blocker) were adopted for intervention treatment in ischemic rats and HEK-293T-ha $\beta_{4}$ cells. Morris Water Maze (MWM) test and 2-[18F]-A-85380 PET imaging were performed to detect the cognition and $a_{4} \beta_{2} n A C h R s$ in ischemic rats. The results demonstrated that nicotine intervention increased the density of $a_{4} \beta_{2}$ nAChRs and improved cognitive impairment, but this effect would be blocked by AG490, while receptors were still upregulated. Essentially, when JAK2-STAT3 signaling pathway was blocked, nicotine could only upregulate the expression of $a_{4} \beta_{2} n A C h R s$, but not improve the cognitive function. The results were further confirmed by PCR and Western blot analysis. The cell experiments also showed that nicotine could reduce inflammatory factors stimulated by LPS and upregulate the expression of pJAK2 and pSTAT3 in HEK-293T-ha $\beta_{4} \beta_{2}$ cells, while AG490 and DHßE reversed nicotine's effect. In summary, our work indicated that JAK2-STAT3 signaling pathway played an important role in nicotine-induced cognitive improvement by up-regulating $a_{4} \beta_{2}$ nAChRs in ischemic rats.

\section{Introduction}

Vascular cognitive impairment $(\mathrm{VCl})$ refers to the contribution of any severity of vascular pathology to any degree of cognitive impairment[1], ranging from cognitive impairment to dementia. It is the second leading cause of dementia after Alzheimer's disease in Western countries, and may be the predominant one in East Asia[2]. Cholinesterase inhibitors and the N-methyl Daspartate antagonist memantine are involved in symptomatic treatment of $\mathrm{VCl}$, however, they showed little benefit on cognition improvement in randomized controlled trials[2]. Recent studies showed that nicotine could play an important role in protection of cognitive function[3-6]. Nicotine is an agonist of neuronal nicotinic acetylcholine receptors (nAChRs), which are composed of five subunits arranged around a water-filled pore. The most abundant nAChR subtypes in the mammalian brain are heteromeric $a_{4} \beta_{2} n A C h R s$ and homomeric $a_{7} n A C h R s$, and $a_{4} \beta_{2}$ is the most abundant subtype in the CNS and with high affinity for nicotine[7-9]. Histopathological studies have shown that under ischemic conditions, inflammation caused by microglia overactivation can destruct the blood-brain barrier, cause brain damage and prompt the occurrence and development of VCI[10-13]. Our prior studies have confirmed that the chronic ischemic cognitive dysfunction was correlated with the decrease of $a_{4} \beta_{2} n A C h R s[14]$, and nicotine played a role in inhibiting the inflammatory factors, which contributes to improving cognitive impairment by activating $a_{4} \beta_{2}$ nAChRs in ischemic rats[15]. How $a_{4} \beta_{2}$ nAChRs activated by nicotine acts on inflammatory factors remains uncertain.

Janus tyrosine kinase 2/signal transducer and activator of transcription 3 (JAK2-STAT3) signaling pathway is known to be a chain of interactions between proteins in a cell, and is involved in processes such as immunity, cell division, cell death and tumor formation. Abnormal activation of JAK2-STAT3 signaling pathway is often closely related to the occurrence, development and prognosis of inflammatory diseases, tumors, autoimmune diseases, etc.[16-18]. Studies have shown that JAK2 and STAT3 can regulate the plasticity of hippocampal synapses and are closely related to learning and memory[19]. Recent studies have also found that JAK2-STAT3 signaling pathway is involved in cognitive improvement[20-23], and JAK2STAT3 signaling pathway is proposed to play a role in the activation of $a_{3}-a_{5}$ - and $a_{7}-n A C h R s[24-28]$. There seems a relationship between $a_{4} \beta_{2}$ nAChRs and JAK2-STAT3 as well[29, 30].

In this study, we aimed to explore the relationship between JAK2-STAT3 signaling pathway and $a_{4} \beta_{2}$ nAChRs activation induced by nicotine in ischemic rats and inflammatory cells. Nicotine, $\mathrm{DH} \beta E$ (the most potent competitive antagonist of $a_{4} \beta_{2}$ nAChRs[31, 32]) and AG490 (a specific JAK2-STAT3 blocker[33, 34]) were adopted for intervention treatment in ischemic rats and inflammatory cells, and 2-[8 F]-A-85380 micro-PET imaging was performed for detecting $a_{4} \beta_{2} n A C h R s[35]$ in ischemic rats. 


\section{Results}

\subsection{Animal Experiments}

\subsubsection{MWM test indicated nicotine improving cognition but blocked by $\mathrm{DH} \beta E$ and AG490}

Normality was checked using the Shapiro-Wilk test, which showed that the data fit a normal distribution. We assumed normal distribution since the sample size was too small to test the normality assumption properly. Using variance analysis of repeated measurement design data to analyze the latency in directional navigation experiment, the escape latency of rats in each group decreased with the increase of experimental days, but the interaction between time and groups had no statistical significance $(F=0.058, p=0.99>0.01)$, indicating that the time factors did not vary with the grouping. There were significant differences in escape latency between different groups $(\mathrm{F}=4.942, p=0.01<0.05)$ (Table 1$)$. The escape latency of rats in the nicotine group and the sham operation group was shorter than ischemic rats treated with saline only, and the difference was statistically significant $(p<0.05)$ (Table 1, Fig. 1). There was no significant difference in escape latency between rats in the nicotine+DH $\beta E$ group, $\mathrm{DH} \beta E$ group, nicotine+AG490 group and AG490 group compared with ischemic rats given saline $(p>0.05)$.

Table 1

Results of MWM test in all groups

\begin{tabular}{|c|c|c|c|c|c|c|c|}
\hline \multirow{3}{*}{$\begin{array}{l}\text { Groups } \\
\text { ischemia } \\
\text { group }\end{array}$} & \multirow{3}{*}{$\begin{array}{l}\text { Number } \\
6\end{array}$} & \multicolumn{4}{|c|}{ Escape latency(seconds) } & \multirow{2}{*}{\multicolumn{2}{|c|}{$\begin{array}{l}\text { Times crossing Time in } \\
\text { target } \\
\text { target quadrantquadrant(s) }\end{array}$}} \\
\hline & & \multirow{2}{*}{$\begin{array}{l}\text { 2nd day } \\
84.04 \pm 44.10\end{array}$} & \multirow{2}{*}{$\begin{array}{l}\text { 3rd day } \\
78.96 \pm 44.93\end{array}$} & \multirow{2}{*}{$\begin{array}{l}\text { 4th day } \\
73.46 \pm 42.00\end{array}$} & \multirow{2}{*}{$\begin{array}{l}\text { 5th day } \\
60.50 \pm 42.88\end{array}$} & & \\
\hline & & & & & & $2.33 \pm 0.94$ & $27.85 \pm 13.32$ \\
\hline $\begin{array}{l}\text { nicotine } \\
\text { group }\end{array}$ & 6 & $50.67 \pm 37.91^{*}$ & $41.46 \pm 37.38 *$ & $35.38 \pm 30.11 *$ & $26.46 \pm 24.93^{*}$ & $5.50 \pm 2.06^{*}$ & $52.51 \pm 7.56^{*}$ \\
\hline $\begin{array}{l}\text { nicotine }+ \\
\text { DH } \beta E \text { group }\end{array}$ & 6 & $83.67 \pm 44.69$ & $72.17 \pm 45.98$ & $61.17 \pm 42.62$ & $48.83 \pm 37.19$ & $3.17 \pm 2.41$ & $30.18 \pm 8.34$ \\
\hline $\mathrm{DH} \beta E$ group & 6 & $82.67 \pm 39.84$ & $76.51 \pm 39.40$ & $65.59 \pm 40.90$ & $53.78 \pm 33.44$ & $3.21 \pm 2.54$ & $33.23 \pm 5.09$ \\
\hline $\begin{array}{l}\text { nicotine + } \\
\text { AG490 } \\
\text { group }\end{array}$ & 6 & $73.04 \pm 41.07$ & $69.33 \pm 47.04$ & $52.75 \pm 39.69$ & $46.92 \pm 39.08$ & $2.67 \pm 1.70$ & $36.57 \pm 11.22$ \\
\hline $\begin{array}{l}\text { AG490 } \\
\text { group }\end{array}$ & 6 & $77.38 \pm 41.24$ & $72.42 \pm 43.53$ & $61.54 \pm 44.01$ & $49.83 \pm 33.14$ & $2.83 \pm 1.34$ & $33.71 \pm 6.55$ \\
\hline $\begin{array}{l}\text { sham } \\
\text { operation } \\
\text { group }\end{array}$ & 6 & $29.21 \pm 17.85^{\star}$ & $25.67 \pm 24.05^{\star}$ & $19.74 \pm 14.53^{*}$ & $11.20 \pm 9.21^{*}$ & $5.90 \pm 0.98 *$ & $55.35 \pm 11.72^{\star}$ \\
\hline
\end{tabular}

The results of space exploration experiment: the number of times that the rats crossed the target quadrant and the activity time in the target quadrant area were listed in Table 1. There were significant differences in the number of times crossing the target quadrant and the activity time in target quadrant in the nicotine group and sham operation group compared with the ischemia group ( $p<0.05)$. There was no significant difference in the nicotine+DH $\beta E$ group, DH $\beta E$ group, nicotine+AG490 group and AG490 group compared with the ischemia group $(p>0.05)$, indicating that nicotine improved the cognitive function of ischemic rats, but the effect was blocked by DHßE and AG490.

\subsubsection{Micro-PET imaging showed nicotine up-regulating $\alpha_{4} \beta_{2} n A C h R s$ was blocked by DHßE not AG490}


The uptake of 2-[18 F]-A-85380 in left thalamus and whole brain of rats in the nicotine group, nicotine+AG490 group and sham operation group was significantly higher than ischemic rats treated with saline only $(p<0.05)$ (Fig. 2, Table 2). There was no significant difference between the nicotine+DHßE group, the $D H \beta E$ group and the AG490 group compared with the ischemia group $(p>0.05)$.

Table 2

Quantitative analysis of micro-PET imaging

\begin{tabular}{|c|c|c|}
\hline Groups & SUV $_{\text {ave left thalamus }} / \mathrm{SUV}_{\text {ave cerebellum }}$ & $\mathrm{SUV}_{\text {ave whole brain }} / \mathrm{SUV}_{\text {ave cerebellum }}$ \\
\hline ischemic group & $2.38 \pm 0.08$ & $1.60 \pm 0.06$ \\
\hline nicotine group & $2.82 \pm 0.13^{\star}$ & $1.73 \pm 0.09 *$ \\
\hline nicotine + DHßE & $2.43 \pm 0.11$ & $1.59 \pm 0.06$ \\
\hline $\mathrm{DH} \beta \mathrm{E}$ group & $2.39 \pm 0.15$ & $1.57 \pm 0.08$ \\
\hline nicotine + AG490 & $2.80 \pm 0.06^{*}$ & $1.76 \pm 0.04^{*}$ \\
\hline AG490 group & $2.31 \pm 0.04$ & $1.60 \pm 0.04$ \\
\hline sham operation group & $2.75 \pm 0.19 *$ & $1.73 \pm 0.18^{*}$ \\
\hline
\end{tabular}

Note: Each group was compared in pairs, only the nicotine group, nicotine+AG490 group and the sham operation group were statistically significant compared with the ischemia group. *: $p<0.05$ versus the ischemia group.

\subsubsection{Real-time PCR indicated nicotine upregulating $\alpha_{4} \beta_{2} n A C h R s$ blocked by DH $\beta E$ not AG490}

Real-time PCR was performed to determine the relative expression of receptor subunits $a_{4}$ and $\beta_{2}$-nAChR in the left thalamus of rats. Three samples in each group were detected, and three technical replications for each sample were performed. The average $C T$ values were obtained by amplifying $\beta$-actin and $a_{4^{-}}, \beta_{2}$-nAChR respectively. The results (Table 3 , Fig. 3 ) showed that the expression of $a_{4}$-and $\beta_{2}$-nAChR mRNA were lower in ischemic rats given saline (ischemia group) than in the sham operation group $(0.51 \pm 0.04,0.68 \pm 0.04)$. The expression of $a_{4}$ - and $\beta_{2}-n A C h R$ mRNA in the left thalamus of rats in nicotine group was significantly higher than rats in ischemia group $(0.75 \pm 0.16, p<0.05 ; 0.86 \pm 0.11, p<0.05)$. The expression levels of $a_{4}{ }^{-}$ and $\beta_{2}$-nAChR mRNA in left thalamus of rats in nicotine+AG490 group were still significantly higher than ischemic rats given saline $(0.74 \pm 0.07, p<0.05 ; 0.82 \pm 0.03, p<0.05)$, and there was no significant difference between nicotine+AG490 and nicotine groups, suggesting that nicotine could increase the number of $a_{4}$ - and $\beta_{2}$-nAChR, while AG490 could not block this function. The expression of $a_{4}$-and $\beta_{2}-n A C h R$ mRNA in left thalamus of nicotine+DHBE group, DH $\beta E$ group and AG490 group was significantly lower than nicotine and nicotine+AG490 groups, but there was no significant difference compared with ischemia group. 
Table 3

RT-PCR results: the relative expression of $a_{4-}$ and $\beta_{2}$-nAChR mRNA in left thalamus of each group $(n=3)$

\begin{tabular}{|lll|}
\hline Groups & $\boldsymbol{a}_{4}$-nAChR & $\beta_{2}$-nAChR \\
\hline ischemia group & $0.51 \pm 0.04$ & $0.68 \pm 0.04$ \\
\hline nicotine group & $0.75 \pm 0.16^{*}$ & $0.86 \pm 0.11^{*}$ \\
\hline nicotine + DH $\beta E$ & $0.56 \pm 0.14$ & $0.57 \pm 0.08$ \\
\hline DH $\beta E$ group & $0.50 \pm 0.02$ & $0.56 \pm 0.02$ \\
\hline nicotine + AG490 & $0.74 \pm 0.07 *$ & $0.83 \pm 0.02^{*}$ \\
\hline AG490 group & $0.51 \pm 0.08$ & $0.67 \pm 0.05$ \\
\hline sham operation group & $1.00 \pm 0.12^{*}$ & $0.98 \pm 0.18^{*}$ \\
\hline $\begin{array}{l}\text { Note: Relative expression means the mRNA expression of each index in different group relative to the normal rats which } \\
\text { was the control group in RT-PCR. Each group was compared in pairs, only the nicotine, nicotine+AG490 and sham operation } \\
\text { groups were statistically significant compared with the ischemia group. *: } p<0.05 \text { versus the ischemia group. }\end{array}$ \\
\hline
\end{tabular}

\subsubsection{Western blot showed nicotine inhibiting inflammation by $a_{4} \beta_{2}$ nAChRs upregulation and activation of JAK2-STAT3 signaling pathway}

Western blot was performed to detect the relative expression of protein $\alpha_{4^{-}}$and $\beta_{2}$-nAChR, IL-1 $\beta$, IL-6, JAK2, STAT3, p-JAK2 and p-STAT3 in the left thalamus of rats. The internal reference was $\beta$-actin. Three samples were collected from each group, and the expression of each group was obtained by gray level detection. Western blot results (Table 4, Fig. 4) showed that the expression of $a_{4}-n A C h R$ and $\beta_{2}$-nAChR protein in nicotine and nicotine+AG490 groups was significantly higher than ischemic rats treated with saline only $(1.91 \pm 0.18, p<0.05 ; 2.05 \pm 0.12, p<0.05 ; 1.88 \pm 0.12, p<0.05 ; 1.91 \pm 0.03, p<0.05)$. The expression levels of $p$-JAK2 and p-STAT3 protein in nicotine group were significantly higher than ischemic rats given saline $(0.95 \pm 0.03$, $p<0.05 ; 1.12 \pm 0.02, p<0.05)$. The expression of $p-J A K 2$ and $p$-STAT3 protein in nicotine+DH $\beta E$ group, nicotine+AG490 group and AG490 group was not significantly different from rats in ischemia group. The expression of IL-1 $\beta$ and IL-6 protein in left thalamus of rats in nicotine group was lower than ischemia group $(0.67 \pm 0.02, p<0.05 ; 1.17 \pm 0.03, p<0.05)$, while the relative expression of inflammatory factors in nicotine+DHBE group, nicotine+AG490 group and AG490 group was not significantly different from ischemia group $(p>0.05)$. These results suggested that the inflammatory response in the brain was enhanced after thalamic ischemia in rats. After nicotine intervention, $a_{4} \beta_{2} n A C h R s$ in the brain was up-regulated, and JAK2-STAT3 signaling pathway was then activated by $a_{4} \beta_{2} n A C h R s$, thus reducing the expression of inflammatory factors in the brain. 
Table 4

Western blot results: the relative expression of protein $\alpha_{4}$ - and $\beta_{2}$-nAChR, IL-1 $\beta$, IL-6, JAK2, STAT3, p-JAK2, p-STAT3 in ischemic thalamus of each group $( \pm s) \square n=3 \square$

\begin{tabular}{|c|c|c|c|c|c|c|c|c|}
\hline Groups & $a_{4}-n A C h R$ & $\beta_{2}$-nAChR & IL-1 $\beta$ & IL-6 & JAK2 & p-JAK2 & STAT3 & p-STAT3 \\
\hline $\begin{array}{l}\text { ischemia } \\
\text { group }\end{array}$ & $1.44 \pm 0.05$ & $1.53 \pm 0.10$ & $0.85 \pm 0.03$ & $1.65 \pm 0.08$ & $1.44 \pm 0.04$ & $0.57 \pm 0.01$ & $1.32 \pm 0.01$ & $0.68 \pm 0.02$ \\
\hline $\begin{array}{l}\text { nicotine } \\
\text { group }\end{array}$ & $1.91 \pm 0.18 *$ & $2.05 \pm 0.12^{\star}$ & $0.67 \pm 0.02^{*}$ & $1.17 \pm 0.03^{\star}$ & $1.42 \pm 0.05$ & $0.95 \pm 0.03^{*}$ & $1.30 \pm 0.01$ & $1.12 \pm 0.02 \star$ \\
\hline $\begin{array}{l}\text { nicotine } \\
+\mathrm{DH} \beta E\end{array}$ & $1.39 \pm 0.09$ & $1.47 \pm 0.11$ & $0.82 \pm 0.02$ & $1.64 \pm 0.05$ & $1.40 \pm 0.07$ & $0.61 \pm 0.07$ & $1.32 \pm 0.01$ & $0.68 \pm 0.05$ \\
\hline $\begin{array}{l}\text { nicotine } \\
+ \text { AG490 }\end{array}$ & $1.88 \pm 0.12^{\star}$ & $1.91 \pm 0.03^{\star}$ & $0.81 \pm 0.01$ & $1.58 \pm 0.02$ & $1.41 \pm 0.06$ & $0.62 \pm 0.04$ & $1.35 \pm 0.05$ & $0.66 \pm 0.02$ \\
\hline $\begin{array}{l}\text { AG490 } \\
\text { group }\end{array}$ & $1.42 \pm 0.18$ & $1.51 \pm 0.10$ & $0.82 \pm 0.01$ & $1.61 \pm 0.03$ & $1.42 \pm 0.06$ & $0.60 \pm 0.01$ & $1.31 \pm 0.02$ & $0.63 \pm 0.02$ \\
\hline
\end{tabular}

\subsection{Cell Experiment}

\subsubsection{Over-expression of CHRNA4 and CHRNB2 in HEK-293T Cells}

For assuring our cell model, the mRNA and protein level of HEK-293T cells are reported. Initial experiments confirmed that the HEK-293T-ha $\beta_{4} \beta_{2}$ cells were expressing the $a_{4} \beta_{2}$ subunit proteins and mRNA. Western blot analysis using $a_{4}$-specific and $\beta_{2}$ specific antibodies confirmed the over-expression of the human $a_{4}$ subunit and $\beta_{2}$ subunit in HEK-293T-ha $\beta_{2}$ cells (Fig. 5A, D). Real-time PCR was used to verify the difference in $\beta_{2}$-nAChR and $a_{4}$-nAChR transcription levels between HEK-293T-ha $\beta_{4} \beta_{2}$ cells stable strain and HEK-293T cells not infected with lentivirus (Fig. 5C, F). The expression of $a_{4}$ - and $\beta_{2}$-nAChR on HEK-293Tha4 $\beta 2$ cells were also confirmed by immunofluorescence staining (Fig. 5B, E).

\subsubsection{JAK2-STAT3 Mediates $a_{4} \beta_{2}$-Mediated Anti-Inflammation}

From the results of western blot (Fig. 6), we can see that when stimulating HEK-293T-ha $\beta_{2} \beta_{2}$ cells with the bacterial endotoxin LPS, the inflammatory factors expressed more, such as IL-6 and TNF-a, suggesting the success of establishing inflammatory cells. To explore the involvement of JAK2-STAT3 in $\mathrm{a}_{4} \beta_{2}$-mediated anti-inflammation, AG490 and DHßE were adopted for intervention treatment. HEK-293T- ha4 $\beta 2$ cells were stimulated with $10 \mu \mathrm{g} / \mathrm{ml}$ LPS for $24 \mathrm{~h}$ at $37^{\circ} \mathrm{C}$, then incubated with nicotine, nicotine+AG490, nicotine+DH $\beta E$. Nicotine can decrease the inflammatory factors, as its anti-inflammatory effect, while AG490 and DHBE restores LPS-induced inflammation in western blots (Fig. 6). Nicotine upregulated the expression of pJAK2, p-STAT3 and $\beta_{2}$-nAChR, but AG490/DH $\beta$ E reversed nicotine's effect (Fig. 6). According to these results, we can conclude that JAK2-STAT3 mediates $\mathrm{a}_{4} \beta_{2}$-mediated anti-inflammation.

\section{Discussion}

Neuroinflammation is an important part of ischemic stroke[36]. Ischemia quickly induces primary irreversible tissue damage, and following the acute focal brain injury is a secondary immune response characterized by glial activation, recruitment of peripheral immune cells, and release of cytokines and chemokines[40]. Nowadays, studies have shown that neuroinflammation is closely related to cognitive impairment[37-39], especially the activation of microglia is the key point leading to neuroinflammation. Anti-inflammatory therapy has also been used to treat cognitive impairment. Guan Y.Z.[40] et al. 
found that nicotine could inhibit the release of inflammatory factors by inhibiting the increment of microglia after nicotine intervention.

Our previous studies $[14,15]$ showed that the cognitive impairment in ischemic rats induced by ET-1 was correlated with the impairment of $a_{4} \beta_{2} n A C h R s$. Appropriate dose of nicotine could improve the learning and memory ability of ischemic rats. This improvement of cognition was related to the increased density of $a_{4} \beta_{2} n A C h R s$ in the thalamus and whole brain after nicotine intervention[15]. When thalamic ischemia happened, the inflammatory response in rat brain was elevated. Nicotine further inhibited the expression of inflammatory factors by activating the $a_{4} \beta_{2} n A C h R s$, thereby improving cognitive function[15]. How nicotine activates $\alpha_{4} \beta_{2} n A C h R s$ is our main work in this study.

JAK-STAT signaling pathway is an important target of a variety of human diseases. In the central nervous system, this signaling pathway is closely related to brain inflammation and the survival and development of neurons/glial cells[41]. It has been found that JAK2 and STAT3 can regulate synaptic plasticity in hippocampus, which is closely related to learning and memory, and JAK2-STAT3 signaling pathway is involved in cognitive improvement[20-23]. Therefore, more and more attention has been paid to the role of JAK2-STAT3 signaling pathway in central nervous system diseases, including Alzheimer's disease, depression and anxiety disorders. AG490 is a specific antagonist of JAK2 and one of the PTK inhibitors[33]. As a specific blocker of JAK2-STAT3 signaling pathway, AG490 inhibits the phosphorylation of JAK2 and STAT3 downstream of JAK2, thereby blocking cell signal transduction[42].

In this study, we established a rat model of ischemic cognitive impairment induced by ET-1 and a HEK-293T cell line with upregulated CHRNA4 and CHRNB2 expression transduced by lentivirus, and explored the relationship between neuroprotective mechanism of nicotine, $a_{4} \beta_{2} n A C h R s$, inflammation and JAK2-STAT3 signaling pathway. In animal experiment, MWM test showed that the learning and memory ability was significantly improved by nicotine intervention, but no significant improvement was observed when nicotine was given with DHßE together, or with AG490 together. 2-[ $\left.{ }^{18} \mathrm{~F}\right]-\mathrm{A}-85380$ PET imaging showed that $a_{4} \beta_{2}$ nAChRs increased significantly in rats brain when nicotine was given alone, or with AG490 together. The study demonstrated that nicotine intervention increased the density of $a_{4} \beta_{2} n A C h R s$ and improved cognitive impairment, but this effect would be blocked by AG490, while receptors were still upregulated. Essentially, when JAK2-STAT3 signaling pathway was blocked, nicotine could only upregulate the expression of $a_{4} \beta_{2} n A C h R s$, but not improve the cognitive function. The results were further confirmed by PCR and Western blot analysis. Furthermore, in cell experiment, nicotine reduced the inflammatory factor such as TNF-a, IL-6 stimulated by LPS in HEK-293T-ha ${ }_{4} \beta_{2}$ cells, while AG490 and DH $\beta E$ reversed nicotine's effect. Nicotine upregulated the expression of pJAK2, pSTAT3 and $\beta_{2}$-nAChR, but AG490 and DH $\beta E$ reversed nicotine's effect as well. Our findings suggest that nicotine can perform anti-inflammation effect and improve ischemic cognitive impairment by up-regulating $a_{4} \beta_{2}$ nAChRs, thereby activating JAK2-STAT3 signaling pathway to reduce inflammatory factors. Therefore, $a_{4} \beta_{2}$ nAChRs-JAK2-STAT3 signaling pathway plays an important role in inhibiting inflammation in ischemic rats and inflammatory cells.

Neuroinflammation is also a feature of many other neurodegeneration diseases, such as Alzheimer's disease, and reducing neuroinflammation is arousing wide attention in treating dementia. Recent study has shown the role of nAChRs in Alzheimer's disease[43], which provides ideas for new targets in the treatment of dementia.

One of the limitations in this study is that immunofluorescence co-staining assay was not performed to provide more direct evidence to confirm if nicotine acts via $a_{4} \beta_{2} n A C h R s$ in immune cells (microglia, astrocyte) or in neurons, for some study demonstrated the overexpression of $a_{4} \beta_{2} n A C h R s$ in both microglia and astrocytes from days 7-28 after experimental ischemic stroke[44]. The reaction of JAK2-STAT3 in immune cells taken from the ischemic region also needs to be investigated further. Another area needs to be further explored is that this study could not confirm the effect of JAK2-STAT3 activating by $a_{4} \beta_{2} n A C h R s$ was direct or indirect, for example, where nicotine affects the expression of another protein that then activates the JAK2-STAT3 pathway. 


\section{Conclusion}

In ischemic rats, nicotine could activate JAK2-STAT3 signaling pathway by up-regulating $a_{4} \beta_{2}$ nAChRs to inhibit the expression of inflammatory factors, thereby improving cognitive function. Nicotine attenuating inflammation by up-regulating $\alpha_{4} \beta_{2}$ nAChRs and activating the JAK2-STAT3 pathway was also confirmed in HEK-293T-ha $\beta_{4} \beta_{2}$ cells.

\section{Methods And Materials 5.1 Animal Experiments}

All animal experiments were approved by the Ethics Committee of The First Hospital of China Medical University, and all experiments were performed in accordance with relevant guidelines and regulations.

\subsubsection{Laboratory Animals and Groups}

Forty-seven male Sprague-Dawley (SD) rats, about 8 weeks old, weighing $250 \pm 20 \mathrm{~g}$, were ordered (China Medical University animal laboratory, SYXK (Liao)2008-0005, Shenyang, China) to SPF animal laboratory. Before the experiment, the rats were fed freely and given $12 \mathrm{~h}-12 \mathrm{~h}$ light-dark cycle.

Ischemic models were established by injecting ET-1 (MERCK, USA) into the left thalamus, the steps in detail were described in the previous study[15]. The model of sham operation group was established: the specific method was the same as above, but ET-1 was replaced by normal saline. On the first day after operation, nicotine (Sigma Aldrich), DHBE (ApexBio, USA), AG490 (SELLECK, USA) or saline were administered according to different grouping: nicotine group (nicotine, $1.5 \mathrm{mg} / \mathrm{kg} / \mathrm{d}$ ),

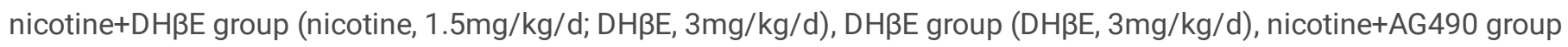
(nicotine, $1.5 \mathrm{mg} / \mathrm{kg} / \mathrm{d} ; A G 490,3 \mathrm{mg} / \mathrm{kg} / \mathrm{d}$ ), AG490 group (AG490, $3 \mathrm{mg} / \mathrm{kg} / \mathrm{d}$ ), ischemia group (saline, $0.8 \mathrm{ml} / \mathrm{kg} / \mathrm{d}$ ) and sham operation group (saline, $0.8 \mathrm{ml} / \mathrm{kg} / \mathrm{d}$ ). Each group consisted of 6 rats and all 42 rats received the intervention by intraperitoneal injection for nine consecutive days.

The other 3 SD rats did not receive any intervention neither operation nor drugs and they were used as a control group for PCR test. Another two rats were sacrificed 24 hours after surgery only for histological analysis with HE staining to make sure the success of ischemic model (Fig. 7), one from the sham operation group, the other from ischemia group.

\subsubsection{Morris Water maze experiment}

On the fourth day of drug intervention, Morris water maze (MWM) (endocrinology laboratory, China Medical University) test was performed to test the spatial learning and memory ability of rats. Rats of different groups were subjected to six consecutive days of experiments, which were divided into the following two parts:

Directional navigation experiment: the experiment lasted for 5 days. On the first day, a directional navigation program was set up. Rats were put into the pool from any two quadrants to familiarize themselves with the water maze environment. Platform was placed in the center of a quadrant of the pool. The training tests were conducted at the same time every day for the next four days. The software automatically recorded the swimming trajectory and swimming time of each rat in the pool.

The space exploration experiment: on the sixth day of the experiment, after setting up the space exploration program, the platform was removed, and the rats were put into any quadrant (except the target quadrant where the original platform was located). The software automatically recorded and analyzed the times that the rats crossed the target quadrant and the activity time in target quadrant in 120 seconds.

\subsubsection{2-[18 $\mathrm{F}]-\mathrm{A}-85380$ Micro PET imaging}


After the MWM test, rats in each group underwent 2-[18 F]-A-85380 micro-PET imaging (Shandong Madic Technology Co., Ltd, China) on the 6th day of MWM. 2-[18 $\mathrm{F}]-\mathrm{A}-85380$ was synthesized according to the previous report[45], which included the synthesis program, the information of the average yield, specific activity, chemistry and radiochemistry necessary for the synthesis. The radiochemical purity of the product 2-[18F]-A-85380 was $98.94 \%$, which can meet the imaging requirements of 2-[18F]-A-85380.

Micro PET imaging was performed with a spatial resolution of $1.3 \mathrm{~mm}$ in the transverse and axial directions and field of vision (Transaxial: $128 \mathrm{~mm}$, axial:59 mm). $37 \mathrm{MBq} 2-\left[{ }^{18} \mathrm{~F}\right]-\mathrm{A}-85380$ was injected by tail vein of rats. Head scan was performed for 10 minutes after 120 minutes.

Quantitative analysis: Drawing ROI was based on standard rat brain atlas by Paxinos[46]. The cerebellum was used as the reference area, and the ratio of the average SUV $\left(S_{U V} V_{\text {ave }}\right)$ in each area to the SUV ave of the cerebellum was calculated. The distribution of 2-[ $\left[{ }^{18} \mathrm{~F}\right]-\mathrm{A}-85380$ in the left thalamus and the whole brain of each group was quantitatively analyzed.

\subsubsection{Real-Time PCR Detection of Receptor Subunits of nAChRs}

The RNA extraction was performed firstly, followed by the reverse transcription synthesis of cDNA. The mixture was homogenized and the sample was placed on a reverse transcription instrument at $37^{\circ} \mathrm{C}, 15 \mathrm{~min} ; 85^{\circ} \mathrm{C}, 5 \mathrm{~s} ; 4^{\circ} \mathrm{C}, 10 \mathrm{~min}$. Realtime PCR amplification curve and dissolution curve were confirmed after the reaction, and the CT value of the sample was calculated automatically by software. RNAiso plus (NO.9108/9109), SYBR Premix Ex Taq II (RR820A), Prime Script RT Reagent Kit (\#RR037A) were purchased from TaKaRa company, Japan. Primers used for the study were as follows:

$a_{4}$-nAChR: F: 5'-ATGGATGAAACCTACCTGATGAGCA-3'

R: 5'-GCTGGGGGTTGTAGCAGGCAC-3'

$\beta_{2}$-nAChR: F: 5'-CGGGAAGCAGTGGATGGCGTA-3'

R: 5'-GTCCTCCCTCACACTCTGGTCATCA-3'

ß-Actin: F: 5'-CATCCTGCGTCTGGACCTGG-3'

R: 5'-TAATGTCACGCACGATTTCC-3'

\subsubsection{Western blot}

The left thalamic tissue was taken and stored in an Eppendorf tube in a refrigerator at $-80^{\circ} \mathrm{C}$. The tissues of each group were added with $1 \mathrm{ml}$ RIPA buffer and PMSF mixture (RIPA: PMSF=100:1). After homogenizing on ice by tissue homogenizer, the tissues were placed on ice for 30 minutes, centrifuged, $4^{\circ} \mathrm{C}, 15,000 \mathrm{rpm}$ for $15 \mathrm{~min}$. The supernatant was then taken and stored at $-80^{\circ} \mathrm{C}$. According to $\mathrm{BCA}$ protein quantitative standard curve, different samples were adjusted to the same concentration with lysis buffer $\left(3-5 \mu \mathrm{g} / \mu \mathrm{l}\right.$ for each sample). All the samples were denatured by heating at $95^{\circ} \mathrm{C}$ for $10 \mathrm{mins}$, and stored at $-20^{\circ} \mathrm{C}$. Finally, $15-20 \mu \mathrm{l}$ sample was added into each lane to ensure the same amount of protein. Equal amounts of proteins were fractionated by SDS-PAGE electrophoresis apparatus, transferred to PVDF membranes. Immunoblotting was carried out with antibodies against $a_{4}-n A C h R s(1: 500), \beta_{2}$ nAChRs(1:500), IL-1ß(1:2000), IL-6(1:2000), JAK2(1:1000), STAT3(1:1000), pJAK2(1:1000), p-STAT3(1:2000), $\beta$-actin $(1: 1000)$ at $4{ }^{\circ} \mathrm{C}$ for $24 \mathrm{~h}$. The membranes were incubated with corresponding secondary antibodies at room temperature for $1 \mathrm{~h}$. Western blots were developed by enhanced chemiluminescence detection system. Image Lab software was used for gel electrophoresis image analysis. The gray value of the panel was used for quantitative analysis, and the histogram was obtained to show the protein expression of each group in each index. Quantitative analysis was performed basing on three individual samples preparation following with western bloting.

Primary antibodies ( $a_{4}$-nAChR, ab41172; $\beta_{2}$-nAChR, ab189174; IL-1 $\beta$, ab2105; IL-6, ab9324; p-JAK2, ab32101) were purchased from ABCAM company, USA; Primary antibodies (JAK2, D2E12; STAT3,124H6; p-STAT3, D3A7) were from Cell Signaling 
Technology, USA; BCA Protein Assay Kit was from Beyotime Biotechnology Research Institute, China; RIPA Lysis Buffer was from Beyotime Biotechnology Research Institute, China; PMSF was from Beijing Solarbio Science \& Technology company, China.

\subsection{Cell Experiment}

\subsubsection{Cell Culture}

HEK-293T cells were cultured at $37^{\circ} \mathrm{C}$ in condition of $5 \% \mathrm{CO} 2$ and $95 \%$ oxygen in Dulbecco's modified Eagle's medium (DMEM) supplemented with $10 \%$ fetal bovine serum, streptomycin $(100 \mu \mathrm{g} / \mathrm{ml})$, and penicillin $(100 \mathrm{units} / \mathrm{mL})$. The cells were divided into two groups: (1) the control (Con) group: cells without lentiviral infection; (2) the overexpression (OE) group: cells infected with two lentivirus that up-regulated CHRNA4 and CHRNB2 expression.

\subsubsection{Construction of a Stable Cell Line with Up-regulated CHRNA4 and CHRNB2 Expression}

For lentivirus production, HEK-293T cells were co-transfected with PGMLV-CMV-H_CHRNA4-EF1-ZsGreen1-T2A-Puro or PGMLVCMV-H_CHRNB2-EF1-mCheery-T2A-Blasticidin. The plasmids were amplified in E. coli DH5 cells, purified using a Plasmid Maxi Kit (Tiangen, Beijing, China), and transfected into 70\% confluent 293T cells using HG transgene reagent (Genomeditech, Shanghai, China). Lentiviral particles were harvested from the supernatant $72 \mathrm{~h}$ after the transfection and purified by ultracentrifugation. These particles are hereafter referred to as LEN-CHRNA4 and LEN-CHRNB2. Stably infected 293T cells with CHRNB2 were selected using blasticidin $(10 \mu \mathrm{g} / \mathrm{ml}$; Beyotime Biotechnology, CA), which killed the uninfected cells. Real-time PCR and western blotting confirmed that the LEN-CHRNB2-infected 293T cells stably over-expressed CHRNA4.

\subsubsection{RNA Extraction and Quantitative RT-PCR}

The total RNA from cells was extracted using the TRIzol Reagent (Invitrogen, Carlsbad, CA, USA). cDNA was synthesize by RevertAid Reverse Transcriptase (TaKaRa, Tokyo, Japan). Real-time PCR was performed on StepOnePlus Real Time System (Applied Biosystems, Foster City, CA, USA), and the reaction steps are as follows: $95^{\circ} \mathrm{C}$ for $30 \mathrm{~s}$ followed by 40 cycles at $95^{\circ} \mathrm{C}$ for $5 \mathrm{~s}$, and then $60^{\circ} \mathrm{C}$ for $30 \mathrm{~s}$. The primers for RT-PCR to amplify $a_{4}$-nAChR and $\beta_{2}$-nAChR is mentioned above. The primers for GAPDH (internal standard) are as follows.

GAPDH: F: 5'-GAGTCAACGGATTTGGTCGT-3'

R: 5'-TTGATTTTGGAGGGATCTCG-3'

The 2- $\Delta \Delta$ Ct method was used to quantify mRNA expression relative to GAPDH.

\subsubsection{Protein Extraction and Western Blot Analysis}

HEK-293T cells were seeded in 6-well plates. After treatments, the total extracts were extracted according to the protocols supplied by the manufacturer (Sangon, Shanghai, China). Next, identical amounts of proteins were separated by SDS-PAGE and then blotted onto nitrocellulose membranes. The membranes were blocked with $5 \%$ nonfat milk as described elsewhere. They were then incubated with conjugated goat antirabbit antibodies at $4^{\circ} \mathrm{C}$ overnight. Thereafter, the membranes were incubated with the secondary antibody for $1 \mathrm{~h}$ at room temperature. Finally, the membranes were detected using the EZ-ECL.

\subsection{Statistical Analysis}

All statistical analyses were performed using ANOVA of IBM SPSS Statistics. Variance analysis was applied for inter-group comparison and Tukey's method was used for in Multiple Comparison Correction. Shapiro-Wilk test was used to check the normal distribution. At least three individual trials were performed for each experiment and data was represented as mean \pm SD. $p<0.05$ was considered statistically significant. Specific $p$ values were indicated in notes of tables and figures.

\section{Declarations}




\section{Funding}

This study was supported by the National Natural Science Foundation of China (No.81671717, 81974270) and Shanghai Pujiang Program (2019PJD032).

\section{Competing Interests}

The authors have no relevant financial or non-financial interests to disclose.

\section{Author Contributions}

Y.Y.: Conceived and designed the experiments; W.Q.: Performed the animal experiments, the analysis and interpretation of data, and drafted the main manuscript text; G. J.: Performed the cell expreriments; G.S.: Assisted in expreimentas and data analysis, and drafted the manuscript text; W.F., H.T. and L.R.: Assisted in expreiments and data analysis; Z.D.: Synthesized the tracer of 2-[18F]-A-85380; D.Y.: Guided the specific implementation of the experiment.

\section{Data Availability}

The authors confirm that the data supporting the findings of this study are available within the article.

\section{Ethics approval and consent to participate}

Animal care and all experimental procedures were performed in accordance with the Guideline for the Care and Use of Laboratory Animals. All animals received humane care. Study protocols complied with the institution's guidelines and were approved by the Ethics Committee of The First Hospital of China Medical University.

\section{Consent to publish}

All authors have read and agreed to the published version of the manuscript.

\section{Acknowledgements}

None.

\section{References}

1. van der Flier WM, Skoog I, Schneider JA, Pantoni L, Mok V, Chen CLH, Scheltens P (2018) Vascular cognitive impairment. Nat Rev Dis Primers 4:18003. doi: 10.1038/nrdp.2018.3

2. ladecola C, Duering M, Hachinski V, Joutel A, Pendlebury ST, Schneider JA, Dichgans M (2019) Vascular Cognitive Impairment and Dementia: JACC Scientific Expert Panel. J Am Coll Cardiol 73:3326-3344. doi: 10.1016/j.jacc.2019.04.034

3. Araya JA, Ramirez AE, Figueroa-Aroca D, Sotes GJ, Perez C, Becerra J, Saez-Orellana F, Guzman L, Aguayo LG, Fuentealba $\mathrm{J}$ (2014) Modulation of neuronal nicotinic receptor by quinolizidine alkaloids causes neuroprotection on a cellular Alzheimer model. J Alzheimers Dis 42:143-155. doi: 10.3233/jad-132045

4. Vieira-Brock PL, McFadden LM, Nielsen SM, Smith MD, Hanson GR, Fleckenstein AE (2015) Nicotine Administration Attenuates Methamphetamine-Induced Novel Object Recognition Deficits. Int J Neuropsychopharmacol 18. doi: 10.1093/ijnp/pyv073

5. Ciobica A, Padurariu M, Hritcu L (2012) The effects of short-term nicotine administration on behavioral and oxidative stress deficiencies induced in a rat model of Parkinson's disease. Psychiatr Danub 24:194-205

6. Jucaite A, Ohd J, Potter AS, Jaeger J, Karlsson P, Hannesdottir K, Bostrom E, Newhouse PA, Paulsson B (2014) A randomized, double-blind, placebo-controlled crossover study of alpha4beta $2^{\star}$ nicotinic acetylcholine receptor agonist 
AZD1446 (TC-6683) in adults with attention-deficit/hyperactivity disorder. Psychopharmacology 231:1251-1265. doi: 10.1007/s00213-013-3116-7

7. Zoli M, Pucci S, Vilella A, Gotti C (2018) Neuronal and Extraneuronal Nicotinic Acetylcholine Receptors. Curr Neuropharmacol 16:338-349. doi: 10.2174/1570159X15666170912110450

8. Paterson D, Nordberg A (2000) Neuronal nicotinic receptors in the human brain. Prog Neurobiol 61:75-111. doi: 10.1016/s0301-0082(99)00045-3

9. Dani JA (2015) Neuronal Nicotinic Acetylcholine Receptor Structure and Function and Response to Nicotine. Int Rev Neurobiol 124:3-19. doi: 10.1016/bs.irn.2015.07.001

10. Ding YS, Fowler JS, Logan J, Wang GJ, Telang F, Garza V, Biegon A, Pareto D, Rooney W, Shea C, Alexoff D, Volkow ND, Vocci F (2004) 6-[18F]Fluoro-A-85380, a new PET tracer for the nicotinic acetylcholine receptor: studies in the human brain and in vivo demonstration of specific binding in white matter. Synapse 53:184-189. doi: 10.1002/syn.20051

11. Lotfipour S, Mandelkern M, Brody AL (2011) Quantitative Molecular Imaging of Neuronal Nicotinic Acetylcholine Receptors in the Human Brain with A-85380 Radiotracers. Curr Med Imaging Rev 7:107-112. doi: 10.2174/157340511795445676

12. Kant R, Constantinescu CC, Parekh P, Pandey SK, Pan ML, Easwaramoorthy B, Mukherjee J (2011) Evaluation of F-nifene binding to alpha4beta2 nicotinic receptors in the rat brain using microPET imaging. EJNMMI Res 1. doi: 10.1186/2191$219 x-1-6$

13. Jiang Y, Yin Y, Li Y (2015) Clinical research progress of fluoride and iodide 3-[2(S) -azacyclobutane methoxy] pyridine. Chinese Journal of Nuclear Medicine and Molecular Imaging 35:322-325

14. Jiang Y, Diao Y, Yin Y, Huang L, Mo Y, Zhang D, Li Y (2017) The Quantitative Analysis of 2-[18F]-A-85380 nAChRs MicroPET Brain Imaging in Chronic Ischemic Rats with Cognitive Dysfunction in Vivo. Journal of Isotopes 30:110-118

15. Han T, Wang Q, Lai R, Zhang D, Diao Y, Yin Y (2020) Nicotine Induced Neurocognitive Protection and Anti-inflammation Effect by Activating alpha 4beta 2 Nicotinic Acetylcholine Receptors in Ischemic Rats. Nicotine Tob Res 22:919-924. doi: $10.1093 / \mathrm{ntr} / \mathrm{ntz} 126$

16. Wu Y, Xu J, Xu J, Zheng W, Chen Q, Jiao D (2018) Study on the mechanism of JAK2/STAT3 signaling pathway-mediated inflammatory reaction after cerebral ischemia. Mol Med Rep 17:5007-5012. doi: 10.3892/mmr.2018.8477

17. Chen J, Wang S, Su J, Chu G, You H, Chen Z, Sun H, Chen B, Zhou M (2016) Interleukin-32alpha inactivates JAK2/STAT3 signaling and reverses interleukin-6-induced epithelial-mesenchymal transition, invasion, and metastasis in pancreatic cancer cells. Onco Targets Ther 9:4225-4237. doi: 10.2147/ott.S103581

18. Qin K, Chen K, Zhao W, Zhao X, Luo J, Wang Q, Gao C, Li X, Wang C (2018) Methotrexate Combined with 4Hydroperoxycyclophosphamide Downregulates Multidrug-Resistance P-Glycoprotein Expression Induced by Methotrexate in Rheumatoid Arthritis Fibroblast-Like Synoviocytes via the JAK2/STAT3 Pathway. J Immunol Res 2018:3619320. doi: $10.1155 / 2018 / 3619320$

19. Nicolas CS, Peineau S, Amici M, Csaba Z, Fafouri A, Javalet C, Collett VJ, Hildebrandt L, Seaton G, Choi SL, Sim SE, Bradley C, Lee K, Zhuo M, Kaang BK, Gressens P, Dournaud P, Fitzjohn SM, Bortolotto ZA, Cho K, Collingridge GL (2012) The Jak/STAT pathway is involved in synaptic plasticity. Neuron 73:374-390. doi: 10.1016/j.neuron.2011.11.024

20. Cao Y, Wang L, Lin LT, Wang XR, Ma SM, Yang NN, Fan H, Fisher M, Yang JW (2021) Acupuncture attenuates cognitive deficits through a7nAChR mediated anti-inflammatory pathway in chronic cerebral hypoperfusion rats. Life Sci 266:118732. doi: 10.1016/j.Ifs.2020.118732

21. Li X, Sun Y, Jin Q, Song D, Diao Y (2019) Kappa opioid receptor agonists improve postoperative cognitive dysfunction in rats via the JAK2/STAT3 signaling pathway. Int J Mol Med 44:1866-1876. doi: 10.3892/ijmm.2019.4339

22. Patton MS, Lodge DJ, Morilak DA, Girotti M (2017) Ketamine Corrects Stress-Induced Cognitive Dysfunction through JAK2/STAT3 Signaling in the Orbitofrontal Cortex. Neuropsychopharmacology 42:1220-1230. doi: 10.1038/npp.2016.236

23. Zhang Z, Zhou H, Zhou J (2021) Neuritin inhibits astrogliosis to ameliorate diabetic cognitive dysfunction. J Mol Endocrinol 66:259-272. doi: 10.1530/jme-20-0321

Page $12 / 20$ 
24. Bai X, Ju H, Gao L, Xiong Y, Dai R, Huang X, Yang C (2019) Regulation of nicotinic acetylcholine receptor a3 subtype in adipose tissue dysfunction. Prostaglandins Other Lipid Mediat 142:53-58. doi: 10.1016/j.prostaglandins.2019.04.001

25. Zhang Y, Jia Y, Li P, Li H, Xiao D, Wang Y, Ma X (2017) Reciprocal activation of a5-nAChR and STAT3 in nicotine-induced human lung cancer cell proliferation. J Genet Genomics 44:355-362. doi: 10.1016/j.jgg.2017.03.003

26. Chen X, Jia Y, Zhang Y, Zhou D, Sun H, Ma X (2020) a5-nAChR contributes to epithelial-mesenchymal transition and metastasis by regulating Jab1/Csn5 signalling in lung cancer. J Cell Mol Med 24:2497-2506. doi: 10.1111/jcmm.14941

27. Zhang Q, Lu Y, Bian H, Guo L, Zhu H (2017) Activation of the a7 nicotinic receptor promotes lipopolysaccharide-induced conversion of M1 microglia to M2. Am J Transl Res 9:971-985

28. Gupta D, Lacayo AA, Greene SM, Leahy JL, Jetton TL (2018) $\beta$-Cell mass restoration by a7 nicotinic acetylcholine receptor activation. J Biol Chem 293:20295-20306. doi: 10.1074/jbc.RA118.004617

29. Kiguchi N, Saika F, Kobayashi Y, Ko MC, Kishioka S (2015) TC-2559, an a4ß2 nicotinic acetylcholine receptor agonist, suppresses the expression of CCL3 and IL-1 $\beta$ through STAT3 inhibition in cultured murine macrophages. J Pharmacol Sci 128:83-86. doi: 10.1016/j.jphs.2015.04.009

30. Rogers SW, Gahring LC (2015) Upregulation of Nicotinic Acetylcholine Receptor alph4+beta2 through a LigandIndependent PI3Kbeta Mechanism That Is Enhanced by TNFalpha and the Jak2/p38Mapk Pathways. PLoS ONE 10:e0143319. doi: 10.1371/journal.pone.0143319

31. Kutlu MG, Tumolo JM, Cann C, Gould TJ (2018) Differential effects of alpha4beta2 nicotinic receptor antagonists and partial-agonists on contextual fear extinction in male C57BL/6 mice. Psychopharmacology 235:1211-1219. doi: $10.1007 / \mathrm{s} 00213-018-4837-4$

32. Lewis AS, Mineur YS, Smith PH, Cahuzac ELM, Picciotto MR (2015) Modulation of aggressive behavior in mice by nicotinic receptor subtypes. Biochem Pharmacol 97:488-497. doi: 10.1016/j.bcp.2015.07.019

33. Seo IA, Lee HK, Shin YK, Lee SH, Seo SY, Park JW, Park HT (2009) Janus Kinase 2 Inhibitor AG490 Inhibits the STAT3 Signaling Pathway by Suppressing Protein Translation of gp130. Korean J Physiol Pharmacol 13:131-138. doi: 10.4196/kjpp.2009.13.2.131

34. Donegan JJ, Girotti M, Weinberg MS, Morilak DA (2014) A novel role for brain interleukin-6: facilitation of cognitive flexibility in rat orbitofrontal cortex. J Neurosci 34:953-962. doi: 10.1523/JNEUROSCI.3968-13.2014

35. Mo YX, Yin YF, Li YM (2014) Neural nAChRs PET imaging probes. Nucl Med Commun 35:135-143. doi: 10.1097/MNM.0000000000000032

36. Ma Y, Wang J, Wang Y, Yang GY (2017) The biphasic function of microglia in ischemic stroke. Prog Neurobiol 157:247272. doi: 10.1016/j.pneurobio.2016.01.005

37. Wei P, Liu Q, Li D, Zheng Q, Zhou J, Li J (2015) Acute nicotine treatment attenuates lipopolysaccharide-induced cognitive dysfunction by increasing BDNF expression and inhibiting neuroinflammation in the rat hippocampus. Neurosci Lett 604:161-166. doi: 10.1016/j.neulet.2015.08.008

38. Osso LA, Chan JR (2015) Astrocytes Underlie Neuroinflammatory Memory Impairment. Cell 163:1574-1576. doi: 10.1016/j.cell.2015.12.001

39. Cai M, Lee JH, Yang EJ (2019) Electroacupuncture attenuates cognition impairment via anti-neuroinflammation in an Alzheimer's disease animal model. J Neuroinflammation 16:264. doi: 10.1186/s12974-019-1665-3

40. Guan YZ, Jin XD, Guan LX, Yan HC, Wang P, Gong Z, Li SJ, Cao X, Xing YL, Gao TM (2015) Nicotine inhibits microglial proliferation and is neuroprotective in global ischemia rats. Mol Neurobiol 51:1480-1488. doi: 10.1007/s12035-014-88253

41. Yu L, Chen C, Wang LF, Kuang X, Liu K, Zhang H, Du JR (2013) Neuroprotective effect of kaempferol glycosides against brain injury and neuroinflammation by inhibiting the activation of NF-kappaB and STAT3 in transient focal stroke. PLoS ONE 8:e55839. doi: 10.1371/journal.pone.0055839

42. Park JS, Lee J, Lim MA, Kim EK, Kim SM, Ryu JG, Lee JH, Kwok SK, Park KS, Kim HY, Park SH, Cho ML (2014) JAK2-STAT3 blockade by AG490 suppresses autoimmune arthritis in mice via reciprocal regulation of regulatory T Cells and Th17 cells. 
J Immunol 192:4417-4424. doi: 10.4049/jimmunol.1300514

43. D'Angelo C, Costantini E, Salvador N, Marchioni M, Di Nicola M, Greig NH, Reale M (2021) nAChRs gene expression and neuroinflammation in APPswe/PS1dE9 transgenic mouse. Sci Rep 11:9711. doi: 10.1038/s41598-021-89139-x

44. Martin A, Szczupak B, Gomez-Vallejo V, Domercq M, Cano A, Padro D, Munoz C, Higuchi M, Matute C, Llop J (2015) In vivo PET imaging of the alpha4beta2 nicotinic acetylcholine receptor as a marker for brain inflammation after cerebral ischemia. J Neurosci 35:5998-6009. doi: 10.1523/JNEUROSCI.3670-14.2015

45. Huang L, Diao Y, Yin Y, Zhang D, Mo Y, Li Y (2013) Radiosynthesis of 2-[18F]-A-85380 and its biodistribution in mice. Journal of China Medical University 42:777-780

46. Paxinos G, Watson C (2007) The rat brain in stereotaxic coordinates. Academic Press

\section{Figures}
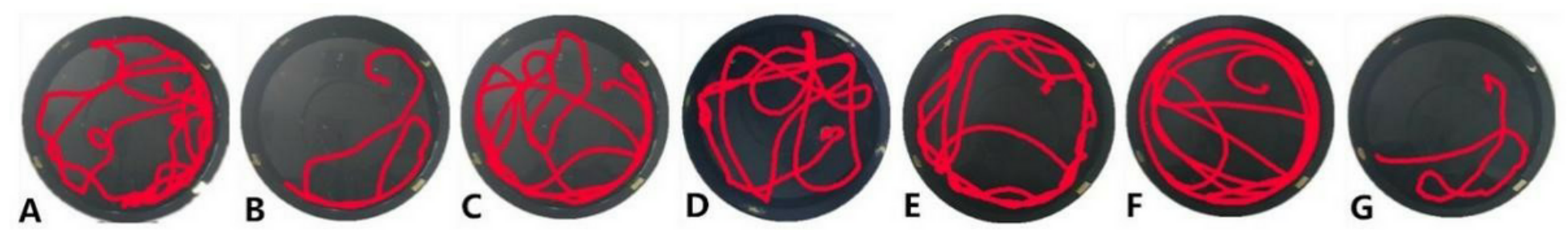

Figure 1

Evasion latency of Morris water maze navigation experiment in rats of each group A-G represents the ischemia group, nicotine group, nicotine + $\mathrm{DH} \beta E$ group, $\mathrm{DH} \beta E$ group, nicotine + $\mathrm{AG} 490$ group, $\mathrm{AG} 490$ group and sham operation group respectively. 


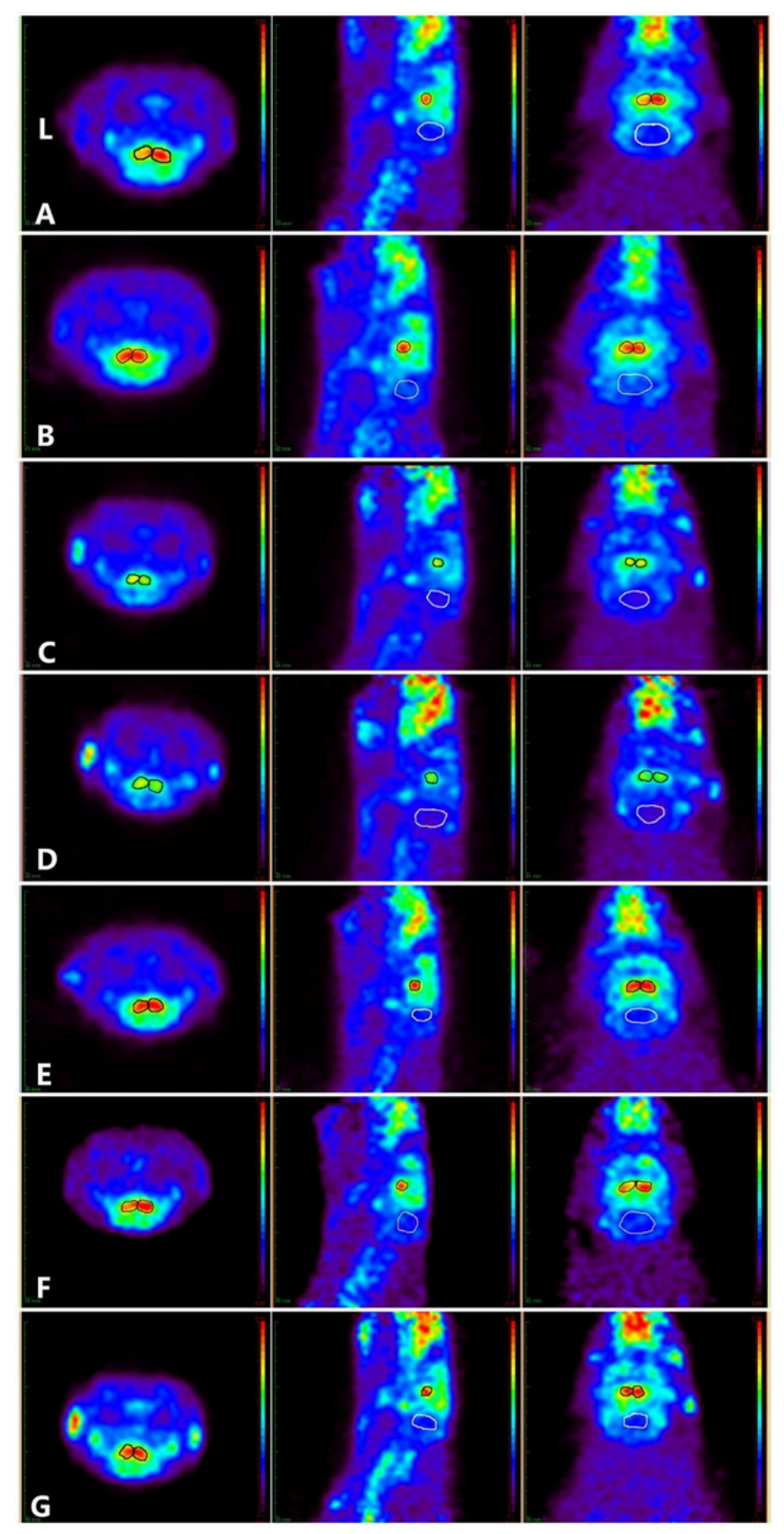

Figure 2

2-[18F]-A-85380 MicroPET imaging in 7 groups $A$ is the ischemia group. The lower uptake of tracer was observed in the left thalamus; $B$ is the nicotine group and $E$ is the nicotine+AG490 group, increased uptake of tracer was observed in the left thalamus; $C$ is the nicotine+DHBE group and $D$ is the $D H \beta E$ group. The uptake of tracer in bilateral thalamus and whole brain was poor; $F$ is the AG490 group. There was a decreased uptake of tracer in the left thalamus, similar as A; $G$ is the sham operation group. The distribution of tracer in bilateral thalamus was uniform and symmetrical. 


\section{$\alpha_{4} \mathrm{nAChR}$}

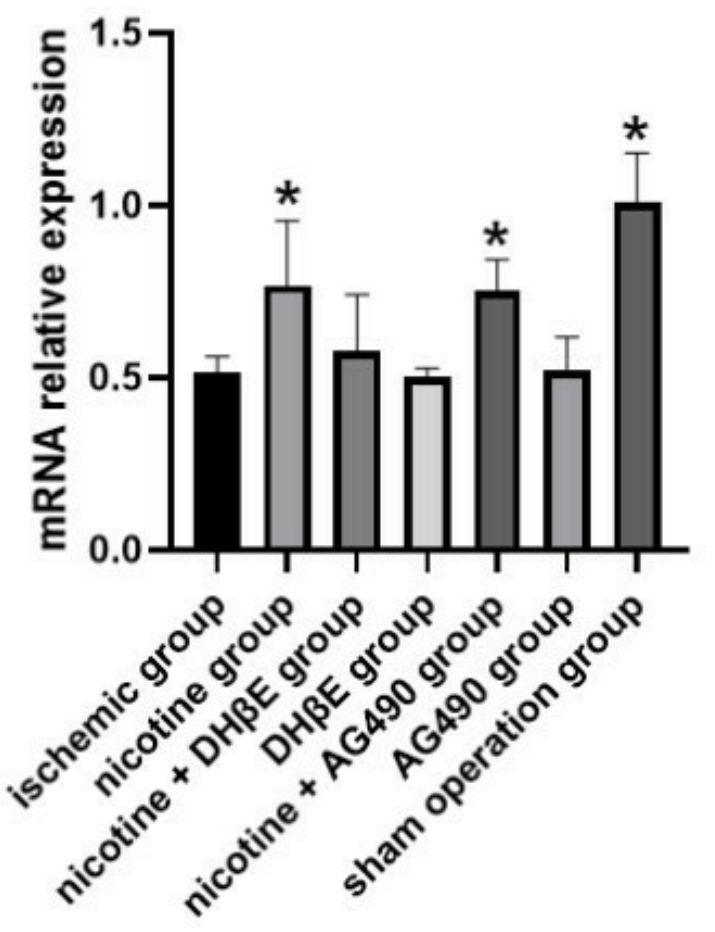

$\beta_{2} \mathrm{nAChR}$
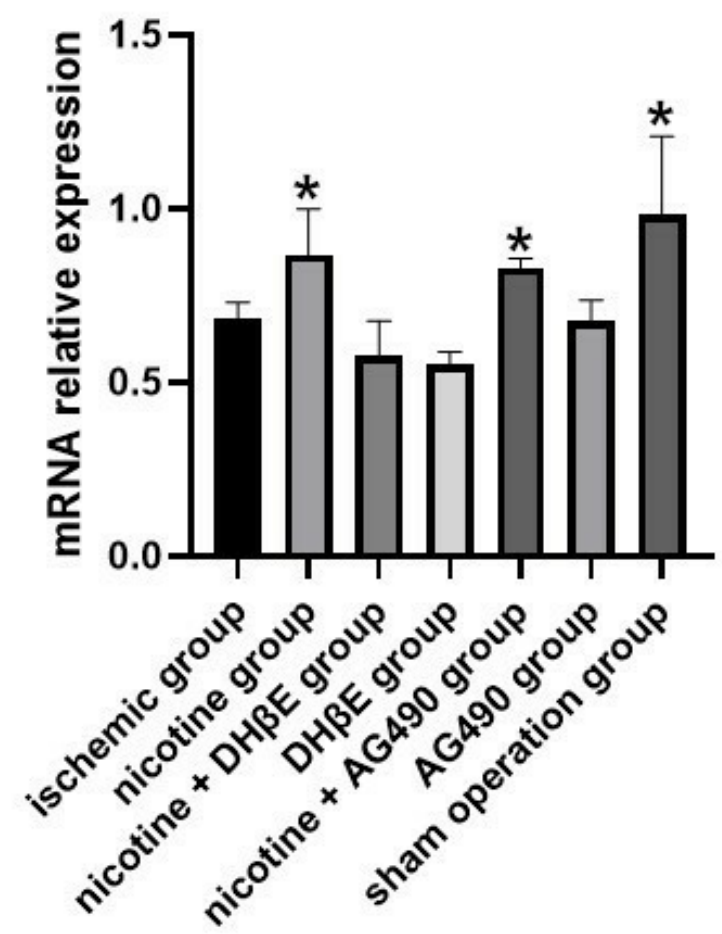

Figure 3

The relative expression of $a 4$ - and $\beta 2-n A C h R$ mRNA in the left thalamus of each group Note: Relative expression was the value of each index in the groups relative to the normal rats which was the control group in RT-PCR. *: $p<0.05$ versus the ischemia group 

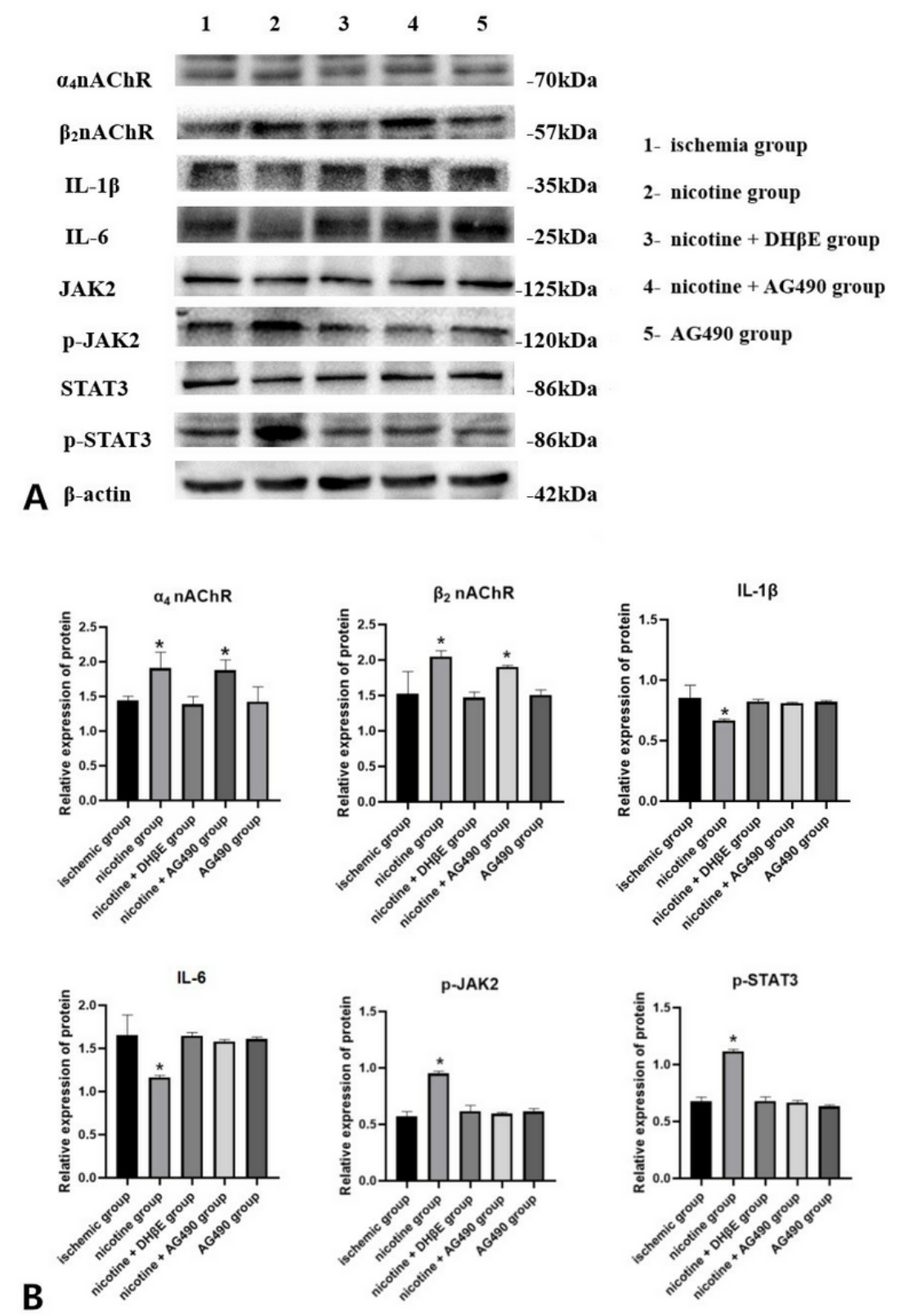

Figure 4

The results of Western Blot A, The protein panel of a4- and $\beta 2$-nAChR, IL-1 $\beta$, IL-6, JAK2, p-JAK2, STAT3, p-STAT3, $\beta$-actin in the left thalamus of each group. $B$, The relative expression of protein $\alpha 4$ - and $\beta 2-n A C h R, I L-1 \beta, I L-6, p-J A K 2, p-S T A T 3$ in the left thalamus of each group. Note: Relative expression was the protein expression of each index relative to $\beta$-actin. $*$ : $p<0.05$ versus the ischemia group. 
A

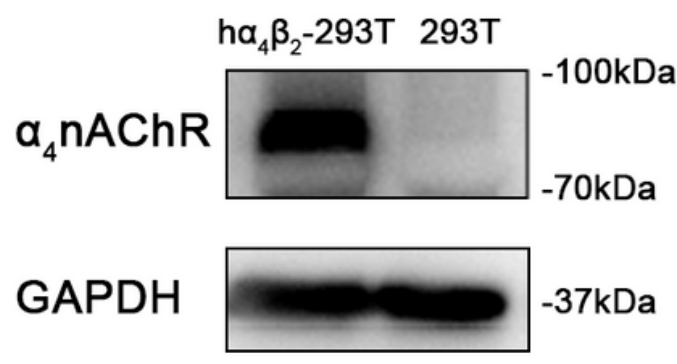

D

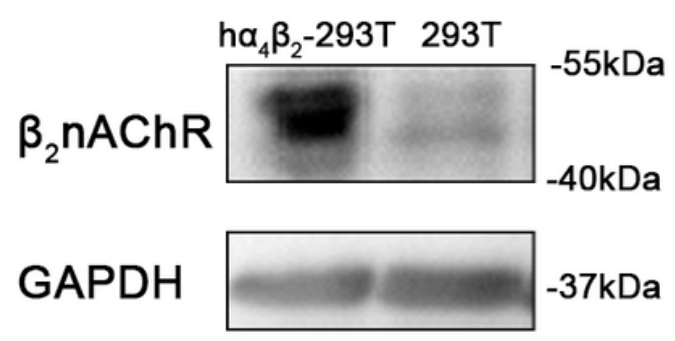

B

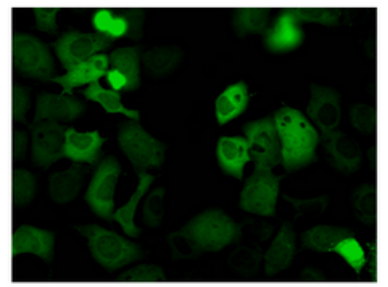

E

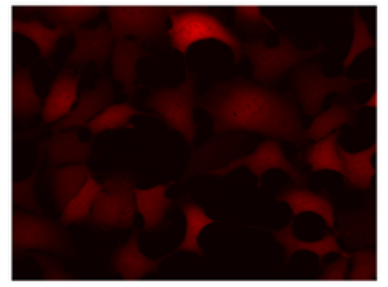

C

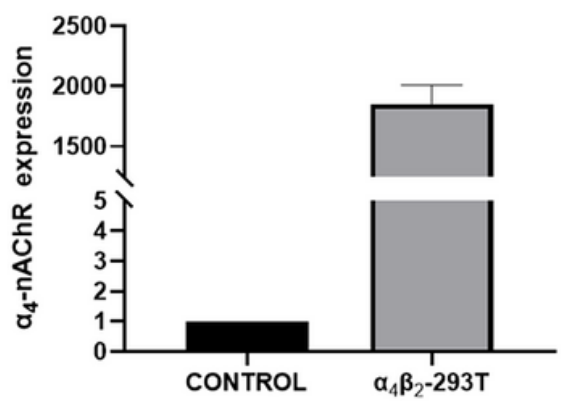

$\mathrm{F}$

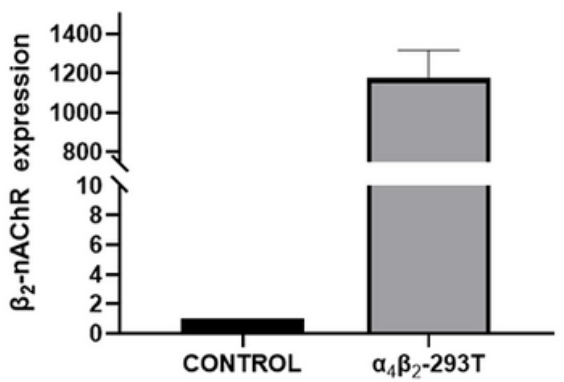

\section{Figure 5}

Over-expression of a4ß2-nAchRs in HEK-293 cell line A, D, Protein levels of a4 subunit (A) and $\beta 2$ subunit (D) in HEK-293Tha4 $\beta 2$ cells and HEK-293T cells not infected with lentivirus were measured in western blot. B, E, Immunofluorescence staining of a4-nAChR (green) and $\beta 2$-nAChR (red) on HEK-293T-ha4ß2 cells. C, F, mRNA of a4-nAChR (C) and $\beta 2$-nAChR (D) in HEK-293Tha4 32 cells stable strain and HEK-293T cells not infected with lentivirus were analyzed by Real-time PCR. 


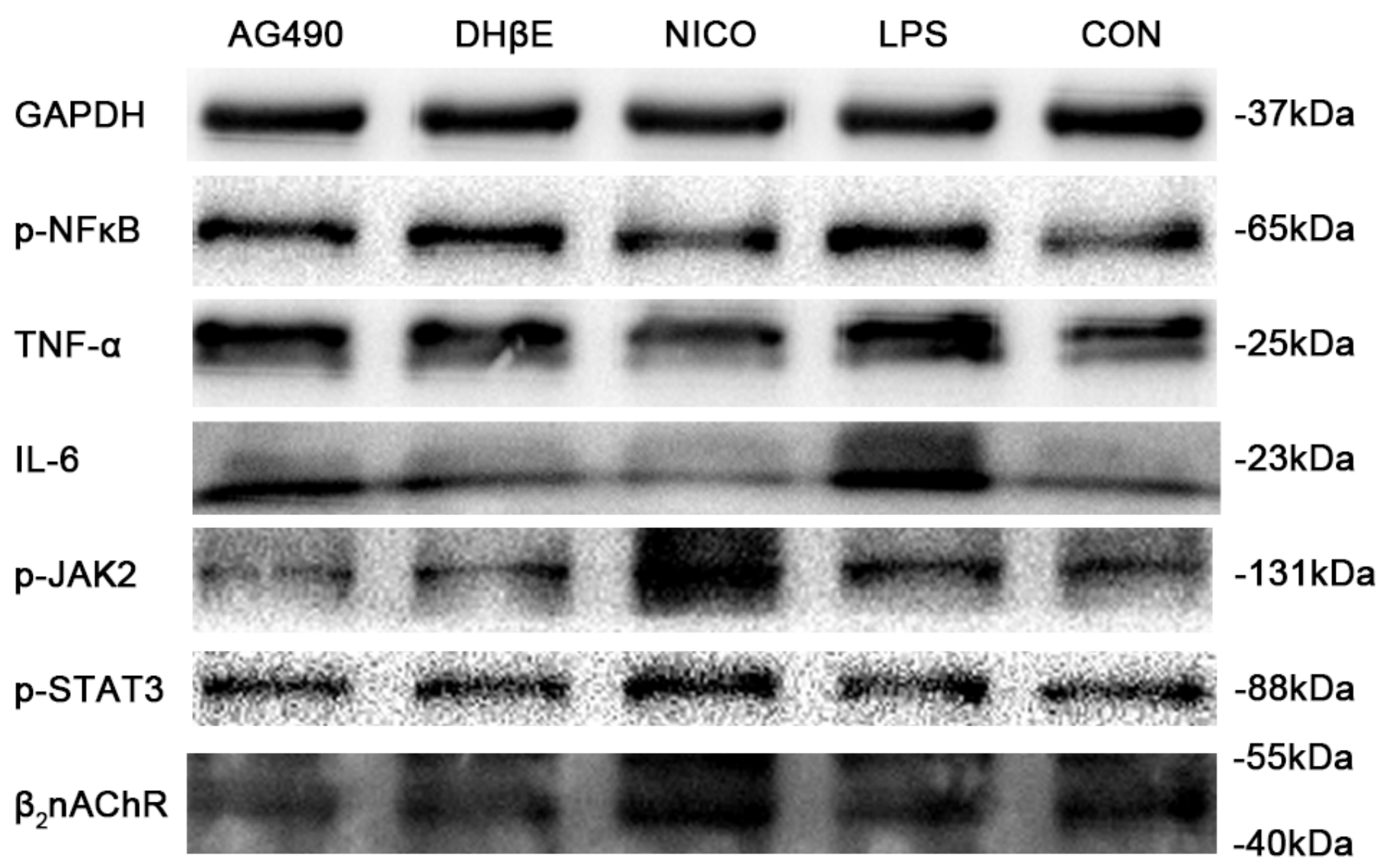

Figure 6

JAK2-STAT3 mediates a4ß2-mediated anti-inflammation HEK-293T-ha4ß2 cells were stimulated with $10 \mu \mathrm{g} / \mathrm{ml}$ LPS for $24 \mathrm{~h}$ and treated with nicotine, nicotine+AG490, and nicotine+DHBE for 24h. Proteins p-NFKB, TNF-a, IL-6, p-JAK2, p-STAT3 and $\beta 2-$ $n A C h R$ were measured in Western blots (GAPDH was the internal reference), suggesting that nicotine blocks LPS-induced inflammation, and upregulates the expression of p-JAK2, p-STAT3 and $\beta 2$-nAChR, but AG490/DHßE reversed nicotine's effect.

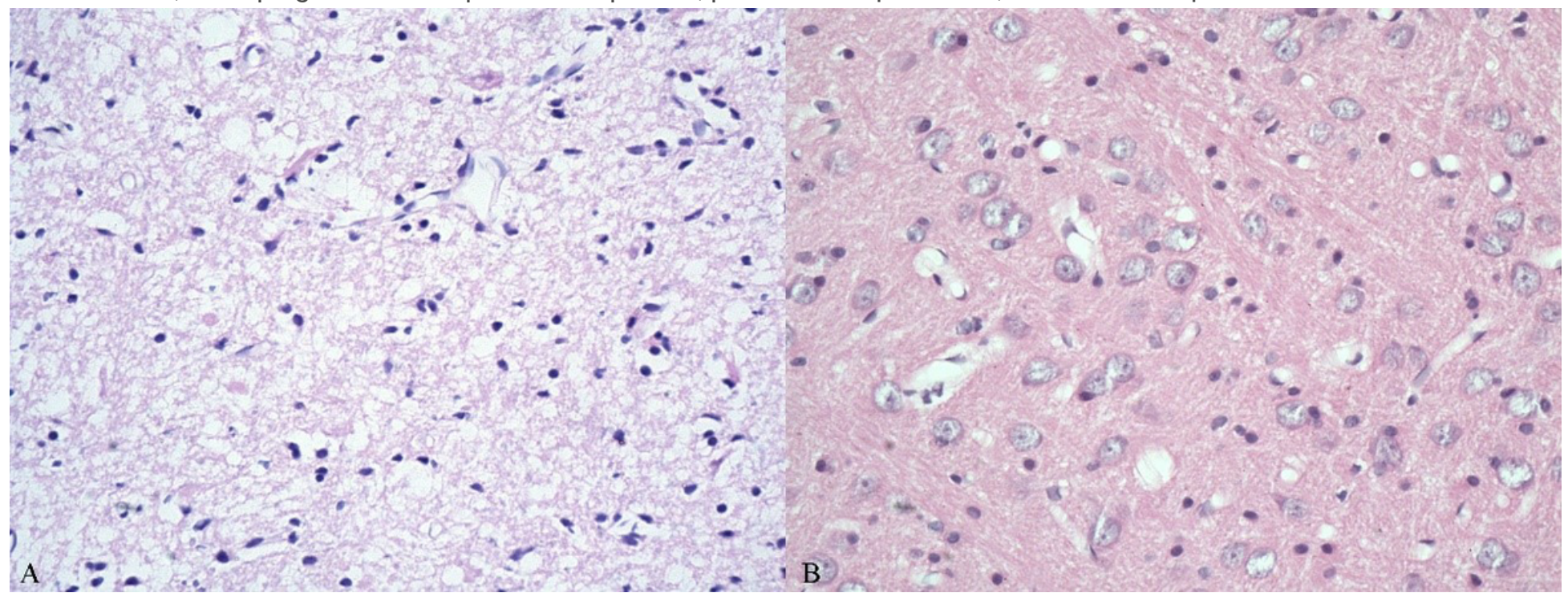

Figure 7 
HE staining images of ischemic rat from the ischemia group (A) and non-ischemic rat from the sham operation group (B) $A$ showed ischemic tissue with many white cells and neurons and glial cells with necrosis or apoptosis. B showed normal tissue without necrotic cells. The ischemic model was successfully established in rat from the ischemia group. 